\title{
As ações do Poder Executivo Federal \\ e o Plano Nacional de Educação (2014/24)
}

\author{
The actions of the Federal Executive
}

and the National Plan for Education (2014/24)

\section{Las acciones del Poder Ejecutivo Federal}

y el Plan Nacional de Educación (2014/24)

\author{
MARIA DILNÉIA ESPÍNDOLA FERNANDES* \\ Universidade Federal de Mato Grosso do Sul, Campo Grande- MS, Brasil. \\ MARLI DOS SANTOS DE OLIVEIRA ${ }^{* *}$ \\ Universidade Federal do Mato Grosso do Sul, Campo Grande- MS, Brasil.
}

\begin{abstract}
RESUMO: Este texto tem por objetivo refletir sobre os rumos e respectivas ações em curso no âmbito do Poder Executivo Federal nos governos de Michel Temer e Jair Bolsonaro no tocante ao monitoramento e avaliação do Plano Nacional de Educação (2014/24). A pesquisa realizou-se por meio de levantamento da literatura, bem como da legislação e demais atos normativos advindos do Governo Federal. Nota-se fragilidades no processo de monitoramento e avaliação do PNE em particular e, de modo geral, nos mecanismos de participação social visto às disputas por projetos distintos de sociedade e de educação.

Palavras-chave: Política educacional. Poder Executivo Federal. Ministério da Educação. Plano Nacional de Educação (2014-2024).
\end{abstract}

* Doutora em Educação. Estágio de Pós-Doutorado realizado na Faculdade de Educação da Universidade de São Paulo. Professora Titular da Universidade Federal de Mato Grosso do Sul. Professora Visitante credenciada no Programa de Pós-Graduação em Educação da Universidade Federal de Mato Grosso do Sul. E-mail:<mdilneia@uol.com.br>.

* Mestre em Educação pela Universidade Federal da Grande Dourados. Doutoranda em Educação na Universidade Federal de Mato Grosso do Sul. Servidora Pública do Instituto Federal de Ciência, Tecnologia e Inovação de Mato Grosso do Sul. E-mail: <marliufms2018@gmail.com>. 


\begin{abstract}
This text aims to reflect on the directions and respective actions underway within the Federal Executive Power in the governments of Michel Temer and Jair Bolsonaro regarding the monitoring and evaluation of the National Plan for Education - PNE (2014/24). The research was conducted through literature review, as well as legislation and other normative acts coming from the Federal Government. There are fraialties in the process of monitoring and evaluation of the PNE in particular and, in general, in the mechanisms of social participation seen in the disputes for distinct projects of society and education.

Keywords: Educational policy. Federal Executive Power. Ministry of Education. National Plan for Education (2014-2024).
\end{abstract}

RESUMEN: Este texto tiene como objetivo reflexionar sobre los rumbos y respectivas acciones en curso en el ámbito del Poder Ejecutivo Federal en los gobiernos de Michel Temer y Jair Bolsonaro con respecto al monitoreo y evaluación del Plan Nacional de Educación (2014/24). La investigación se realizó a través de la revisión de la literatura, así como la legislación y otros actos normativos procedentes del Gobierno Federal. Se observan debilidades en el proceso de monitoreo y evaluación del PNE en particular y, en general, en los mecanismos de participación social frente a las disputas por distintos proyectos de sociedad y educación.

Palabras clave: Política educativa. Poder Ejecutivo Federal. Ministerio de la Educación. Plan Nacional de Educación (2014-2024).

\title{
Considerações iniciais
}

A ruptura democrática em curso no País, iniciada com o impeachment da presidenta Dilma Vana Roussef e robustecida com a vitória de Jair Bolsonaro à Presidência da República Federativa do Brasil, encontra resistências de diversas ordens, sobretudo no contexto das entidades do campo educacional que insistentemente se opõem e se insurgem contra os desmontes em curso (CONFEDERAÇÃO NACIONAL DOS TRABALHADORES EM EDUCAÇÃO, 2019). Inegavelmente, há riscos sem precedentes aos direitos sociais, notadamente aos direitos à e na educação, se considerados os avanços oportunizados com o advento da Constituição Federal da República Federativa do Brasil de 1988 (CRFB/1988). 
As políticas públicas educacionais se forjam e se materializam no bojo das disputas por projetos distintos de sociedade, cujas contradições se fazem presentes, como é próprio da dinâmica social capitalista. Embora as ações no campo educacional durante o governo Dilma Vana Roussef também tivessem apresentado limites e contradições, não se pode negar que as medidas iniciadas com sua destituição e com o advento do governo de Michel Temer sinalizaram uma grave ruptura institucional com o objetivo de descontruir os avanços sociais e educacionais, amparados na CRFB/1988.

Michel Temer, com a rapidez que somente uma ruptura democrática possibilita, adotou medidas prejudiciais aos projetos educacionais, sobretudo na disputa pelo fundo público das reformas administrativa, da previdência e trabalhista. Esta, por sua vez, entrou em vigor no dia 11 de novembro de 2017, nos termos da Lei no 13.467/2017, e alterou uma série de artigos da Consolidação das Leis do Trabalho (CLT) restringindo os direitos trabalhistas (BRASIL, 2017a).

No seio das reformas administrativas de seu curto mandato, extinguiu ministérios, como o da Cultura e o Ministério das Mulheres, da Igualdade Racial, da Juventude e dos Direitos Humanos, aglutinando pastas importantes na implementação de ações com vistas a diminuição da pobreza, da violência e da desigualdade social (BRASIL, 2016a).

No desmonte anunciado das políticas sociais, a Emenda à Constituição no 95 de 2016 (EC no 95/2016) denominada de Teto dos Gastos Públicos, foi aprovada com o propósito de reduzir os gastos sociais nos próximos 20 anos (BRASIL, 2016b). Essa redução implica diretamente o cumprimento das metas estabelecidas no Plano Nacional de Educação (PNE 2014-2024), sobretudo no que concerne à expansão do direito à educação, da educação básica à educação superior, além do estabelecimento do Custo aluno qualidade inicial /Custo aluno qualidade (CAQi, CAQ), bem como a valorização do magistério da educação básica como política obrigatória em todo o território nacional (BRASIL, 2014).

Se não bastassem as medidas adotadas pelo Governo Temer, o resultado das eleições presidenciais de 2018, com a vitória de Jair Messias Bolsonaro, do Partido Social Liberal (PSL), sinaliza maiores percalços à democracia e à educação pública, haja vista o desmonte social da República brasileira anunciado na campanha eleitoral e agora em implementação (PEREIRA, 2019).

Nesse contexto, têm-se sucessivos sinais de neoconservadorismo, isto é, a defesa de valores tradicionais, no tocante à moralidade, aos costumes e à religião. Os direcionamentos e concepções acerca de educação pública defendidas por esse grupo baseiam-se em "visões fundamentadas na autoridade bíblica, moral cristã, as questões de gênero e o papel da família" (PERONI, CAETANO \& ARELARO, 2019, p. 47).

A educação pública em geral e, em particular, o planejamento das políticas educacionais caminham na contramão dos avanços socialmente construídos, sobretudo se analisadas a instabilidade e as medidas recentes no âmbito do Ministério da Educação, com o advento do novo Governo Federal. 
Este texto tem por objetivo refletir sobre os rumos e respectivas ações em curso do Poder Executivo Federal nos governos de Michel Temer e, no contexto atual, do governo de Jair Bolsonaro no Plano Nacional de Educação (PNE) para o decênio (2014-2024).

As alterações provocadas pelo Governo de Michel Temer no seio do Fórum Nacional de Educação e no Conselho Nacional de Educação anunciaram o esvaziamento da materialização do PNE (2014-2024), dada a inviabilização institucional de seu monitoramento e avaliação. No Governo Jair Bolsonaro, as perspectivas sinalizam para o retrocesso dos direitos sociais em geral e, em particular, ao direito à educação, dada à redução significativa de recursos, no contexto do "Novo Regime Fiscal" advindo da Emenda Constitucional no 95/2016, cuja proposta orçamentária para 2020 - Projeto de Lei $n^{0}$ 22/2019-CN ${ }^{1}$ (BRASIL, 2016b, 2019a, 2019b), que estima a receita e fixa a despesa da União para o exercício financeiro de 2020 - evidencia demasiada redução no orçamento do Ministério da Educação.

\section{O Governo e os (des) caminhos do PNE (2014-2024)}

O órgão ministerial responsável pela educação brasileira é o Ministério da Educação (MEC). Dentre suas funções precípuas, está a coordenação da política nacional, conforme atribuições e competências dispostas pela CRFB/1988 e a legislação infraconstitucional (BRASIL, 1988; 1996).

As ações no âmbito da União, notadamente no seio do MEC, exigem uma análise acerca dos condicionamentos e disputas político-partidários travados entre Poder Executivo e Poder Legislativo, observadas as disposições constitucionais sobre a autonomia e interdependência que mantêm, juntamente com o Poder Judiciário, conforme art. $2^{2}$ da CRFB/1988.

A composição e ocupação dos altos cargos dos ministérios da República não observam, necessariamente, aspectos relacionados a experiência e competência acadêmico-profissional dos candidatos para a consecução das ações e a formulação de políticas públicas. Essa questão deve ser analisada, inegavelmente, sob pena de esvaziá-la ou reduzi-la, a luz das disputas político-partidárias e sua consequente configuração no bojo do Poder Executivo e Legislativo.

As bases institucionais do sistema político brasileiro modificaram-se de modo considerável a partir da CRFB/1988, sobretudo na ampliação dos poderes legislativos à disposição do presidente da República e aos recursos legislativos à disposição das lideranças partidárias no comando de suas bancadas no Congresso Nacional, isto é, a unidade de referência para estruturar os trabalhos nas casas legislativas são os partidos e não os parlamentares, necessariamente (FIGUEIREDO, LIMONGI, 1998).

Nessa perspectiva de análise, o Poder Executivo, ao dispor do poder de agenda, domina o processo legislativo e busca os meios necessários à cooperação dos parlamentares. Esse 
poder de agenda implica a influência do Executivo nos trabalhos do Legislativo de modo a determinar a matéria proposta a ser considerada pelo Congresso, como também quando será apreciada. A CRFB/1988 conferiu um extenso rol de matérias e atribuições exclusivas e privativas do presidente da República e da União, nos termos dos arts. 84 e 22, respectivamente.

De acordo com o Art. 64, § 2, o presidente pode solicitar, em caráter de urgência, a apreciação de determinada matéria, no interregno de 45 (quarenta e cinco) dias em cada uma das casas. É justamente esse caráter de urgência que impede as minorias de exercer seu controle de veto points e "engavetar" as propostas presidenciais. Portanto, o presidente da República, além de poder exclusivo em determinadas matérias, dispõe do poder unilateral de requerer a apreciação de matérias no prazo legal determinado.

Inegavelmente, essas prerrogativas exclusivas trazem uma série de implicações, sobretudo se analisadas no contexto do poder de agenda, sem desconsiderar, todavia, que os interesses de Executivo e Legislativo podem se assemelhar e/ou divergir acerca dos projetos de sociedade. Eventualmente, os parlamentares podem se posicionar de acordo com a conveniência eleitoral, em detrimento das preferências partidárias ao qual está filiado, o que interfere ns negociações e disputas entre os poderes Legislativo e Executivo.

No cerne das disputas entre os poderes, não se pode perceber o Executivo como elo fraco no bojo das barganhas políticas, uma vez que ele controla os recursos almejados pelos parlamentares, com vistas à reeleição. Além disso, a formação do governo (distribuição de ministérios, nomeações nos diversos cargos, entre outras situações) guarda relação com a coalização partidária, o que possibilita ao Executivo aprovar suas matérias no Parlamento.

As negociações políticas pressupõem consistências formais entre os poderes, principalmente na votação das propostas governamentais, uma vez que a caneta que nomeia é a mesma que demite, o que afeta diretamente os correligionários e, por consequência, o interesse dos parlamentares.

Essas considerações preliminares acerca de alguns dos diversos condicionantes em que o governo e suas ações se forjam são necessárias a fim de situar o cenário em que o Ministério da Educação e suas ações estão situados. Por certo, a formulação da política de educação nacional não se limita a essas questões, mas não se pode desconsiderar que as intermitências de ordem político-partidária afetam os rumos e prioridades educacionais no País, especialmente os planos decenais de educação e suas metas e estratégias, prioritários à educação.

Notadamente sobre o planejamento educacional e a função da União, a CRFB/1988 dispôs em seu Art. 214 sobre a necessidade de elaborar o Plano Nacional de Educação. No entanto, passados quase dez anos de sua promulgação, foi elaborada uma proposta de PNE construída a partir da realização do II Congresso Nacional de Educação (Coned) em 1997. Denominado de PNE da sociedade civil (PERONI, FLORES, 2014), a proposta expressava, para além das deliberações do I e II Coned, os anseios defendidos pelo Fórum Nacional em Defesa da Escola Pública, no contexto da Assembleia Nacional Constituinte, consubstanciados em dispositivos da CF/1988. 
Diferentemente dessa lógica e dinâmica de construção, a proposta de PNE do Executivo (DUARTE, SANTOS, 2014) foi apresentada ao Congresso Nacional (Projeto de Lei 4.173/1998), cuja elaboração limitou-se ao âmbito do Ministério da Educação em parceria com o Consed e a Undime. De caráter técnico e com proposições segmentadas, seus objetivos e metas evidenciavam a concepção que o governo FHC tinha da educação, consoante sua perspectiva de Estado.

A proposta de PNE do Executivo foi apensada à proposta de PNE da sociedade civil no Congresso Nacional, cuja aprovação se deu sob a forma da Lei no 10.172/2001 (BRASIL, 2001). Essa lei - que instituiu o Plano Nacional de Educação para o decênio - fez-se em prejuízo das propostas apresentadas ao II Coned e, portanto, desconsiderou a trajetória e a lógica democrática da sociedade brasileira para a construção do PNE. Não se tratavam apenas de PNE distintos, mas, evidentemente, de uma disputa, no âmbito da sociedade e do Poder Legislativo, de projetos e concepções distintas de políticas educacionais e de nação.

Embora aprovado pelo Congresso Nacional e sancionado pela Presidência da República, detendo, portanto, de força de lei, o PNE (2001-2010) não se constituiu como "referência-base do planejamento e das políticas educacionais" (DOURADO, 2016, p.18). As indicações contidas no PNE (2001-2010) que atribuíam ao Governo Federal a promoção de avaliações periódicas não foram cumpridas, bem como poucos estados e municípios da federação elaboraram seus respectivos planos decenais de educação conforme preconizava o nacional.

A ausência de um diagnóstico com dados referentes ao efetivo alcance das metas no PNE (2001-2010) por parte do Governo Federal foi sentida pela sociedade no curso das conferências preparatórias à I Conferência Nacional de Educação (Conae). As conferências figuram no cenário dos anos 2000 como mecanismo importante à democratização das relações educacionais e sociais, na medida em que agregam diferentes percepções e anseios na formulação dos planos decenais de educação, como ocorreu com a I e II Conae de 2010 e 2014, respectivamente, que culminaram com a aprovação, em 2014, do Plano Nacional de Educação.

Cumpre registrar que, embora a realização da I e II Conae seja fruto do movimento da sociedade civil, o Governo Federal a viabilizou, na medida em que a institucionalizou e subsidiou financeiramente sua execução.

Após as discussões legislativas, aprovou-se o PNE (2014-2024), instituído pela Lei $\mathrm{n}^{\circ} 13.005$ de 25 de junho de 2014, composto de 20 metas e 254 estratégias. Destina-se a um conjunto de temas discutidos e defendidos historicamente, com vistas a ampliar o direito à educação no País. (BRASIL, 2014).

Além de definir prazos em suas 20 (vinte) metas, há prazos intermediários, que devem orientar o processo de monitoramento e avaliação do PNE (2014-2024). Esses prazos evidenciam o grande esforço a ser empreendido nos diferentes entes subnacionais, com vistas ao alcance das metas e estratégias para a educação no decênio. 


\section{Ministério da Educação: intermitências e rupturas}

A Lei n⿳0 13.005 de 2014, que aprovou o PNE 2014, estabeleceu diretrizes fundamentais, tendo como imperativo a ampliação do direito à educação. Embora o PNE 2014-2024 tenha sido aprovado sem vetos pela presidenta Dilma Rousseff (2011-2016), não se pode desconsiderar as disputas de concepções acerca das relações entre: a) público e o privado, b) diversidade e educação, c) gestão democrática/ restrita ao setor público, d) avaliação da educação básica, e) relação sociedade e educação, f) diversidade étnico-cultural, sexual e de gênero, bem como acerca de uma questão estrutural: o financiamento da educação (DOURADO, 2016).

Após os embates em torno da tramitação e aprovação do PNE 2014-2024 e dos respectivos planos estaduais e municipais, a sociedade brasileira vivencia uma nova fase. Trata-se do momento de monitorar e avaliar os planos decenais com a intencionalidade de verificar as metas e estratégias em curso. Todavia, o momento histórico traz sérias implicações à efetivação dos planos educacionais e fragiliza demasiadamente os processos de construção democrática das políticas públicas sociais conquistados a partir da CRFB/1988.

O presidente Michel Temer $^{2}$ (2016-2018) deu início a uma série de reformas que sinalizam para o retrocesso no que se refere às políticas sociais e à democratização das relações e vão na contramão da participação e do planejamento educacional participativo, estimulado e viabilizado com a realização da Conae, cujo PNE 2014-2024 atribuiu o papel fundamental de avaliar a execução do Plano para, posteriormente, subsidiar a elaboração do PNE subsequente.

O Art. $5^{\circ}$ do PNE (2014-2024) estabeleceu que o cumprimento das metas será objeto de monitoramento contínuo e avaliações periódicas, realizadas pelo Ministério da Educação, Comissão de Educação da Câmara dos Deputados e do Senado Federal, Conselho Nacional de Educação e Fórum Nacional de Educação.

O Art. $6^{\circ}$, por sua vez, traz que o Fórum Nacional de Educação, instituído pelo próprio PNE 2014-2024, articulará e coordenará a realização das conferências nacionais, estaduais, distritais e municipais, além de acompanhar a execução do PNE e o cumprimento das suas metas e promover a articulação das conferências de educação (BRASIL, 2014).

Observando essas disposições, a presidenta Dilma decretara no dia 09 de maio de 2016 a convocatória da $3^{\circ}$ Conferência Nacional de Educação, cujo Art. $8^{\circ}$ dispunha que a coordenação da Conferência seria exercida pela coordenação do Fórum Nacional de Educação. Todavia, Michel Temer revogou esse Decreto, mediante a publicação do Decreto Executivo de 26 de abril de 2017 que dispôs no Art. 8ํㅜ que:

A supervisão e a orientação das atividades de articulação e coordenação dispos-

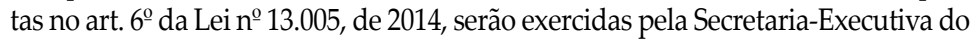
Ministério da Educação, que adotará todas as medidas administrativas e gerenciais 
necessárias ao fiel atendimento dos objetivos da $3^{a}$ Conferência Nacional de Educação contidos no art. $1^{\circ}$, bem como das atribuições especificadas no art. $6^{\circ}$ deste Decreto (BRASIL, 2017b).

A referida alteração contraria o disposto no Art. $6^{\circ}$ do PNE (2014-2024) e subordina o Fórum Nacional de Educação ao Ministério da Educação na condução da Conae prevista para 2018. Um dia após a publicação dessas alterações, o Ministério da Educação emitiu a Portaria n 577, de 27 de abril de 2017 (BRASIL, 2017b), que dispõe sobre o Fórum Nacional de Educação, cuja nova composição, entre outros retrocessos, reduziu a participação da representação da sociedade civil. O FNE, enquanto política de Estado para viabilizar e fortalecer a implementação dos planos decenais de educação "não é um apêndice rebaixado do Ministério da Educação que, por ele, pode ser modificado a qualquer tempo de forma unilateral e arbitrária, para atender quaisquer interesses conjunturais e políticos" (ARAÚJO, 2017, p.02).

Nesse contexto de embates, disputas e rupturas, tem-se um movimento de resistência do Fórum Nacional de Educação ao não aceitar o controle exercido pelo MEC, visto a ilegitimidade do FNE então constituído pela Portaria 577/2017 (BRASIL, 2017b). A não revogação da Portaria e do Decreto 26/2017 fez com que entidades comprometidas com a educação pública viabilizassem a criação do Fórum Nacional Popular de Educação (FNPE) no intuito de pressionar o Governo Federal a viabilizar a implementação dos planos decenais de educação, bem como a organização da Conferência Nacional Popular de Educação (Conape) enquanto espaço de resistência e luta contra os desmontes em curso.

Foi diante desse cenário, que demanda forte contraposição, que se mobilizou a Conferência Nacional Popular de Educação (Conape) como instrumento de resistência, em defesa dos avanços e dos espaços de interlocução conquistados após décadas de muita luta e que agora estão sendo destruídos e/ou usurpados pelo atual projeto político, que vem negando o fortalecimento de uma educação pública, laica, democrática, inclusiva, crítica e de qualidade socialmente referenciada (FORUM NACIONAL POPULAR DE EDUCAÇÃO, 2017, p.02).

Além da ausência histórica de um Sistema Nacional de Educação e das disputas políticas em torno da materialização do PNE 2014-2024, a inviabilização da realização da Conae por parte do Governo Michel Temer no contexto de monitoramento e avaliação do Plano reafirma o desafio à sua execução e ao cumprimento de suas metas e estratégias, cuja participação democrática da sociedade civil e dos sujeitos definidos como responsáveis coloca-se como situação sine qua non para a sua materialização.

Nas ações em curso do Governo Bolsonaro, nota-se que, em pouco mais de 100 (cem) dias de mandato, o MEC registrou dois ministros da Educação, além de demissões no quadro da Secretaria Executiva. Cercado de polêmicas e declarações na contramão dos avanços sociais, o ex-ministro Vélez Rodriguez, em dois meses à frente do ministério: a) fez declarações sobre a necessidade de revisão dos livros didáticos a fim de rever a 
abordagem da ditadura civil-militar de 1964; b) demitiu o secretário executivo e mais de dez outros cargos da pasta, além do presidente do Inep; c) afirmou que as universidades não são espaço para todos, entre outras afirmações preconceituosas, seguidas de pedidos de desculpas amplamente divulgados na impressa nacional (O GLOBO, 2019). O atual ministro da Educação, por sua vez, tem se mostrado tão polêmico quanto o anterior. A diferença entre ambos parece estar em qual etapa da educação concentrar ataques. Enquanto o primeiro se esforçou nesse sentido em relação à educação básica, o atual tem concentrado a maior parte de seus ataques à educação superior. Uma de suas declarações dizia que o Exame Nacional de Ensino Médio (Enem) dá acesso à educação superior de forma seletiva e agora "quer conhecimentos científicos e não tintas ideológicas" (FERREIRA, 2019, p. 01).

Diante desse quadro, a redução do Estado social de Direito e dos direitos sociais que lhe são inerentes situa-se no bojo das complexas relações sociais e econômicas no cenário mundial, cuja dimensão da crise e as respectivas soluções, emanadas em cada Estado em particular, são, inexoravelmente diversas (SARLET, 2009):

\begin{abstract}
[...] uma variante contemporânea do poder neoliberal faz sua a retórica do soberanismo e adotou um estilo populista para reforçar e radicalizar o domínio do capital sobre a sociedade [...] Esta recuperação da cólera e dos ressentimentos requer sem dúvida, para ser realizada efetivamente, o carisma de um líder capaz de encarnar a síntese, outrora improvável, de um nacionalismo econômico, uma liberalização dos mecanismos econômicos e financeiros e uma política sistematicamente pró-empresarial [...] Para alcançar seus objetivos, este poder emprega todos os meios que lhe são necessários: a propaganda dos meios de comunicação, a legitimação pela ciência econômica, a chantagem e a mentira, o descumprimento das promessas, a corrupção sistêmica das elites, etc. (DARDOT, LAVAL, 2019, p. 8-9).
\end{abstract}

No Brasil, cuja justificativa se assenta no "Novo Regime Fiscal", nota-se de modo acentuado o desmonte aos direitos sociais de modo direto e sem precedentes, sob a via da legalidade (BRASIL, 2016b). A título de exemplo, a divulgação da proposta orçamentária para 2020 - Projeto de Lei no 22/2019-CN, que estima a receita e fixa a despesa da União para o exercício financeiro de 2020, apresentado pelo atual governo, aponta uma redução de 18\% dos recursos totais destinados ao Ministério da Educação, em comparação aos valores de 2019 (BRASIL, 2019a).

Tais reduções implicam da educação básica à educação superior, sobretudo no que concerne ao financiamento de pesquisas vinculadas às universidades federais. A saber:

Orçamento de Bolsonaro para 2020 tira metade dos recursos do MEC para pesquisa - Recurso da pasta caiu de R \$ 4,25 bilhões neste ano para R \$2,20 bilhões em 2020 (SALDAÑA, 2019a).

MEC faz novos cortes e não irá financiar nenhum novo pesquisador neste ano Governo Bolsonaro corta 5.600 novas bolsas de pesquisa; bolsas em andamento são mantidas (SALDAÑA, 2019b). 
MEC bloqueia mais verbas e corte já afeta 11,8 mil bolsas de pós-graduação (FORMENTI, 2019).

O Projeto de Lei Orçamentária 2020, encaminhado ao Congresso Nacional em agosto de 2019, apresenta uma redução de 22 bilhões de reais no orçamento do Ministério da Educação, uma vez que os valores aprovados para 2019 foram de $\mathrm{R} \$ 122$ bilhões e, neste Projeto de Lei, os valores previstos são de $\mathrm{R} \$ 101$ bilhões, como se nota na Tabela 01, retirada do orçamento encaminhado ao Congresso.

\section{Tabela 1 - Orçamento do Ministério da Educação (2020)}

\begin{tabular}{l|c|c|c|c|c}
\hline \multicolumn{5}{c}{ Órgão: $\mathbf{2 6 0 0 0}$ - Poder Executivo - Ministério da Educação } \\
\hline \multicolumn{5}{c}{ Quadro Síntese - Recursos de todas as fontes } \\
\hline Código/ & Lei+Crédito & Empenhado & PLO & LOA & PLO \\
especificação & 2018 & 2018 & 2019 & 2019 & 2020 \\
\hline Total & 111.590 .465 .990 & 109.600 .804 .049 & 121.963 .197 .328 & 122.951 .191 .257 & 101.212 .530 .326 \\
\hline
\end{tabular}

Fonte: Elaboração própria com base em Brasil, 2019b.

Especialmente sobre o monitoramento e avaliação do PNE (2014-2024), o presidente Jair Bolsonaro extinguiu o principal órgão responsável por prestar assistência técnica e dar apoio aos municípios , isto é, a Secretaria de Articulação com os Sistemas de Ensino (Sase) que fora criada em 2011, fruto das proposições da Conae de 2010 (DE OLHOS NOS PLANOS, 2019).

Na progressiva materialização do PNE (2014-2024) e do próprio direito à educação, tem-se, no contexto atual, uma ofensiva sem precedentes ao orçamento do Ministério da Educação, cuja redução implicará graves retrocessos sociais.

Os direitos fundamentais devem ser oponíveis a qualquer coalizão política, pois constituem elementos essenciais e porque descrevem exigências indispensáveis a manutenção e funcionamento de um Estado que se quer democrático. Desse modo, em regra, o poder político, em face das cláusulas pétreas que na CRFB/1988 inclui os direitos fundamentais (art. 60, $\S 4^{\circ}, \mathrm{IV}$ ), deve apenas submeter-se e zelar pelo seu cumprimento e progressão, embora as ações em curso sigam na contramão desses axiomas.

\section{Considerações finais}

A (re)democratização da sociedade brasileira, com o processo constituinte, trouxe avanços consideráveis aos direitos sociais. Em decorrência da adoção do modelo de Estado Social adotado na CRFB/198,8 há que se resguardar os direitos individuais e 
sociais; e, desse modo, o papel de destaque conferido aos direitos fundamentais desautoriza sua negação e/ou esvaziamento.

O direito à educação no Brasil é reconhecido como direito fundamental social e detém número expressivo de dispositivos em relação aos demais direitos sociais. Os artigos 205 a 214 da CF/1988 dispõe sobre princípios, atribuições e competências dos entes federados, fontes de financiamento, dentre outras disposições que garantem espaço privilegiado à educação da população brasileira (BRASIL, 1988).

Ao congelar os aumentos reais nos próximos 20 (vinte) anos, a EC nº 95/2016 inviabiliza a progressividade de direitos individuais e coletivos e viola a disposição do Art.

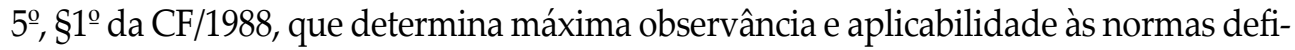
nidoras de direitos e garantias fundamentais (BRASIL, 1988, 2016b).

A defesa e luta histórica em torno do planejamento educacional é fragilizada no contexto da EC n 95/2016, sobretudo sob a perspectiva de cumprimento das disposições constantes no PNE 2014-2024. Suas metas e estratégias evidenciam a necessidade de esforços periódicos e conjuntos, com vistas ao alcance daquilo que se espera para a educação brasileira no decênio. Mais do que uma carta de intenções, o PNE 2014-2024 goza de status jurídico, cuja formulação atendeu aos requisitos legislativos e anseios sociais daqueles que participaram dos amplos debates em contexto municipal, estadual e nacional por meio das conferências.

A atual conjuntura econômica, política, social e cultural forja um novo pacto societário, quando a CRFB/1988 já não pode mais ser a fiadora do acordo nacional inscrito no Estado de direito democrático e social.

Recebido em: 10/10/2019 e Aprovado em: 02/12/2019

\section{Notas}

1 O Projeto de Lei no 22/2019-CN e demais documentos (Volumes, Mensagem Presidencial etc.) estão disponíveis em: <https://www2.camara.leg.br/orcamento-da-uniao/leis-orcamentarias/loa/copy_of_2019/tramitacao/proposta-do-poder-executivo>. Acesso em: 03 de set. 2019.

2 Dilma Vana Rousseff, a primeira mulher a presidir o Brasil, reeleita em outubro de 2014 com 54 milhões de votos, foi destituída da Presidência da República em 31 de agosto de 2016, após uma votação midiática no Senado. Com o resultado - 60 votos a 20 -, Michel Temer, interino desde 12 de maio de 2016, assumiu a Presidência da República de forma definitiva até 2018. 


\section{Referências}

BRASIL. Constituição da República Federativa do Brasil de 1988. Brasília, Presidência da República: 1988.

Casa Civil. Lei n⿳0 $\mathbf{1 0 . 1 7 2}$ de 9 de janeiro de 2001. Aprova o Plano Nacional de Educação e dá outras providências. Brasília, 2001. Disponível em: <http://www.planalto.gov.br/ccivil_03/leis/leis_2001/ 110172.htm>. Acesso em: 24 set. 2019.

. Ministério da Educação. Portaria n⿳0 1.407, de 14 de dezembro de 2010. Institui o Fórum Nacional de Educação - FNE. Brasília, 2010. Disponível em: < http://fne.mec.gov.br/images/pdf/legislacao/ portaria_1407_14122010.pdf >. Acesso em: 05 out. 2019.

Casa Civil. Lei n 13.005 , de 25 de julho de 2014. Aprova o Plano Nacional de Educação - PNE e dá outras providências. Brasília, 2014. Disponível em:<http://www.planalto.gov.br/ccivil_03/_Ato20112014/2014/Lei/L13005.htm>. Acesso em: 26 ago. 2015.

Câmara dos Deputados. Medida provisória fecha em 23 número de ministérios do governo Temer. Brasília, 2016a. Disponível em: < https://www.camara.leg.br/noticias/487882-medida-provisoriafecha-em-23-numero-de-ministerios-do-governo-temer/>. Acesso em: 04 out. 2019.

Casa Civil. Emenda Constitucional no 95, de 15 de dezembro de 2016. Brasília, 2016b. Disponível em: < http://www.planalto.gov.br/ccivil_03/Constituicao/Emendas/Emc/emc95.htm>. Acesso em: 04 out. 2019.Altera o Ato das Disposições Constitucionais Transitórias, para instituir o Novo Regime Fiscal, e dá outras providências.

. Casa Civil. Lei no 13.467, de 13 de julho de 2017. Brasília, 2017a.Altera a Consolidação das Leis do Trabalho (CLT), aprovada pelo Decreto-Lei $n^{\circ} 5.452$, de $1^{\circ}$ de maio de 1943 , e as Leis $n^{\circ}$ 6.019, de 3 de janeiro de 1974, 8.036, de 11 de maio de 1990, e 8.212, de 24 de julho de 1991, a fim de adequar a legislação às novas relações de trabalho. Disponível em: < http://www.planalto.gov.br/ccivil_03/_ato20152018/2017/lei/113467.htm>. Acesso em: 04 out. 2019.

Ministério da Educação. Fundo Nacional de Desenvolvimento da Educação. Portaria MEC № 577, de 27 de abril de 2017. Dispõe sobre o Fórum Nacional de Educação. Brasília, 2017b. Disponível em: < https://www.fnde.gov.br/index.php/acesso-a-informacao/institucional/legislacao/item/10927-portariamec-n\%C2\%BA-577,-de-27-de-abril-de-2017>. Acesso em: 05 out. 2019.

Câmara dos Deputados. Orçamento da União. LOA 2020 - Projeto de Lei nº 22/2019-CN. PL nº 22/2019-CN. Brasília, 2019a. Disponível em: < https://www2.camara.leg.br/orcamento-da-uniao/leisorcamentarias/loa/copy_of_2019/tramitacao/proposta-do-poder-executivo >. Acesso em: 04 out. 2019.

Decreto no 9.465, de 2 de janeiro de 2019. Brasília, 2019b. Disponível em: <http://www.in.gov.br/ materia//asset_publisher/Kujrw0TZC2Mb/content/id/57633286. Acesso em: 04 de abril de 2019.

CONFEDERAÇÃO NACIONAL DOS TRABALHADORES EM EDUCAÇÃO. Manifesto. 9ª Conferência Nacional de Educação Paulo Freire - Educação Libertária e Democrática: construindo o movimento pedagógico Latino-Americano. Curitiba, 2019. Disponível em: < http://fnpe.com.br/wp-content/ uploads/2019/10/Manifesto-da-9\%C2\%AA-Conferencia-Nacional-de-Educacao-da-CNTE-1.pdf >. Acesso em: 10 out. 2019.

DARDOT, Pierre; LAVAL, Christian Laval. Anatomia do novo neoliberalismo. 2019. Disponível em: $<$ http://www.ihu.unisinos.br/78-noticias/591075-anatomia-do-novo-neoliberalismo-artigo-de-pierredardot-e-christian-laval>. Acesso em: 25 de ago. 2019. 
DE OLHO NOS PLANOS. MEC extingue SASE, Secretaria responsável por articular o PNE. Disponível em: < http://www.deolhonosplanos.org.br/mec-extingue-sase/ >. Acesso em: 05 out. 2019.

DOURADO, Luiz Fernandes. Plano Nacional de Educação: política de Estado para a educação brasileira. Brasília-DF: INEP/MEC, 2016.

DUARTE, Marisa Ribeiro Teixeira; SANTOS, Maria Rosimary Soares dos. Planejamento e participação: os eventos nacionais na área da educação após a Constituição de 1988. Educação. Porto Alegre. v.31, n.2, p.167-179, maio-ago, 2014.

FERREIRA, Paula. Enem: ministro quer 'conhecimento científico' e não 'tintas ideológicas' no exame. O Globo. 10/10/2019. Rio de Janeiro, 2019. Disponível em: < https://oglobo.globo.com/sociedade/ educacao/enem-e-vestibular/enem-ministro-quer-conhecimento-cientifico-nao-tintas-ideologicas-noexame-24008632 >. Acesso em: 10 out. 2019.

FIGUEIREDO, Fernando. LIMONGI, Argelina. Bases institucionais do presidencialismo de coalização. Lua Nova, [online], n, 44, pp.81-106, 1998. http://dx.doi.org/10.1590/S0102-64451998000200005.

FORMENTI, Ligia. MEC bloqueia mais verbas e cortes já afeta 11,8 mil bolsas de pós-graduação. $\mathbf{O}$ Estado de São Paulo. 02/07/2019. São Paulo, 2019. Disponível em: < https://educacao.estadao.com.br/ noticias/geral,mec-bloqueia-mais-verbas-e-corte-ja-afeta-11-8-mil-bolsas-de-pos-graduacao,70002993596>. Acesso em: 05 out. 2019.

Relembre as polêmicas da gestão Vélez Rodríguez no Ministério da Educação. O GLOBO. Sociedade. Educação. Atualizado em 26/02/2019. Disponível em: < https://oglobo.globo.com/sociedade/educacao/ relembre-as-polemicas-da-gestao-velez-rodriguez-no-ministerio-da-educacao-23481992 >. Acesso em: 05 out. 2019.

PEREIRA, Roger. Desmatamento, fome, desemprego. Os números do próprio governo que Bolsonaro contesta". Gazeta do Povo. Brasília, 19-07- 2019. Disponível em: < https://www.gazetadopovo.com.br/ republica/bolsonaro-contesta-numeros-desmatamento-fome-desemprego/>. Acesso em: 04 out. 2019.

PERONI, Vera Maria Vidal; FLORES, Maria Luiza Rodrigues. Sistema nacional, plano nacional e gestão democrática da educação no Brasil: articulações e tensões. Educação. Porto Alegre. v.31, n.2, p.180-189, maio-ago, 2014.

PERONI, Vera Maria Vidal; CAETANO, Maria Vidal; ARELARO, Lisete Regina Gomes. BNCC: disputa pela qualidade ou submissão da educação? RBPAE. v.35. n.1, p. 035-056. Jan. abr. 2019. Disponível em: <file:///C:/Users/3136745/Downloads/93094-381308-1-PB.pdf>. Acesso em: 27 de set. 2019.

SALDAÑA, Paulo. Orçamento de Bolsonaro para 2020 tira metade dos recursos do MEC para pesquisa. Folha de São Paulo. 02/07/2019. São Paulo, 2019a. Disponível em: < https://www1.folha.uol.com.br/ educacao/2019/09/orcamento-de-bolsonaro-para-2020-tira-metade-dos-recursos-do-mec-para-pesquisa. shtml>. Acesso em: 05 out. 2019.

. MEC faz novos cortes e não irá financiar nenhum novo pesquisador neste ano. Folha de São Paulo. 02/07/2019. São Paulo, 2019b. Disponível em: < https://www1.folha.uol.com.br/educacao/2019/09/ mec-faz-novos-cortes-e-nao-ira-financiar-nenhum-novo-pesquisador-neste-ano.shtml >. Acesso em: 05 out. 2019. 